\title{
Yüksek Öğretim ve Yaygın Eğitim İşbirliği: Annemin Masalı
}

Celile Eren ÖKTEN ${ }^{*}$

Öz

Bu çalışmanın temelini, Esenler Belediyesi Şehir Düşünce Merkezi ile Yıldız Teknik Üniversitesi'nin birlikte geliştirdiği bir sosyal sorumluluk çalışması olan, eğitimlerine devam edemeyip ara vermiş annelerin yaygın eğitimlerine katkıda bulunmayı hedefleyen "Anne Üniversitesi" teşkil etmektedir. Annelere üniversite - örgün eğitim ortamında dokuz modül halinde sanat, sağlık, medya, iletişim gibi konularda eğitimler verilmiştir. Bu çerçevede yaygın-yetişkin eğitimi uygulamaları adına annelerden kendi masallarını yazmaları istenerek yaratıcı-çözümleme düşünce biçimleri, ifade güçleri, öz-öğrenmeleri ve sosyal değerleri üzerindeki farkındalıklarının arttırılması hedeflenmiştir. Anneler, eğitimleri boyunca sınıf içinde gözlemlenmiş; sınıf içi performansları değerlendirilmiş ve yapılan değerlendirme sonucunda 25 masal anlatım bütünlügü ve verdiği eğitim mesajı bakımından basılmaya uygun bulunmuştur. Annelerin masalları, tematik inceleme ile değerlendirildikten sonra kendileri ile masalların yazım süreçleri üzerine sözlü ve yazılı görüşmeler yapılmış; tümevarımsal tematik inceleme yöntemi ile içerikteki temalar, görüşmeler sonucunda elde edilen verilerle karşılaştırılarak yaygın eğitimin masalların oluşumundaki katkısı incelenmiştir.

Anahtar Kelimeler: Yaygın Eğitim, Yetişkin Eğitimi, Masal, Öğrenme Alanları.

\section{Higher Education And Non-Formal Education Collaboration: My Mother's Tale}

\begin{abstract}
The guiding principal of this research was shaped by "Mother University", a civil society project, which was conducted by Yıldız Technical University and City \& Thought Center of Esenler Municipality, in order to aim to provide non-formal education opportunity to the mothers who had been obliged to suspend their formal education. The mothers were taught with nine modules such as art, health, media, communication, etc. at the university - formal education environment. In this framework of the practices of non-formal education, the mothers were asked to write their own tales
\end{abstract}

\footnotetext{
* Yrd. Doç. Dr., Yıldız Teknik Üniversitesi Eğitim Fakültesi, Yabancı Diller Eğitimi Bölümü, cargit@yildiz.edu.tr ** Marmara Üniversitesi Sosyal Bilimler Enstitüsü Mahalli İdareler ve Yerel Yönetimler Yüksek Lisans Öğrencisi: sevilacar@yandex.com
} 
in order to raise their awareness on their own creative and analytic thinking styles, capability of self-expression, self-learning and social values. Thus, the tale study would become an educational outcome through adding experiences to module lectures. The mothers were observed during the whole educational period; their classroom performances were evaluated and consequently, twenty five tales were approved to be publish with regard to their narrative coherence and educational message. After the tales were examined with the inductive thematic analysis method, the mothers were interviewed orally and in written about the process of writing tales. The themes received from the content were compared with the results of the interviews with the help of inductive themativ analysis. Thus, the contribution of non-formal education was evaluated in writing process of the tales.

Keywords: Non-formal education, Adult education, Tale, Learning domains.

\section{GİRIŞ}

Yaygin eğitim, toplumda belirgin bir işlevsellikle tanımlanmayan, eğitimini çeşitli sebeplerden dolayı tamamlayamamış olan yetişkinlere eğitim olanaklarını sunan hayat boyu öğrenim stratejilerindendir (Eurydice, 2011). Bu bağlamda yaygın-yetişkin eğitimi, sosyo-kültürel bir uygulama ile etkinlik haline getirilmesi hem kişisel gelişim hem de hayat boyu öğrenme açısından anlamlı bir organizasyondur. Yaygın eğitimin kültür, sosyal ağ, uygulama ve ürün verme ile ilişkilendirilmesi hayat boyu eğitim programının belirgin bir parçası olan yetişkin eğitiminin verimliliği açısından önem taşımaktadır (Eloranta, 2013; Knox, 2002; Ngaka, Openjuru ve Mazur, 2012).

Böylelikle yaygın eğitim, bireyi çoklu öğrenme ortamlarına hazırlamakta ve örgün eğitim sistemine girişini mümkün kılmaktadır (Vermeersch ve Vandenbroucke, 2009). Bu çalışma, yetişkin eğitimine farklı bir bakış açısı getirerek öğrenicinin performansını daha verimli kılmada örnek teşkil etmekte, hayat-tecrübe merkezli öğrenimi desteklemekte, aynı zamanda yaygın eğitim ve yükseköğretim işbirliğinin geliştirilmesine katkıda bulunmaktadır (Knowles, Holton ve Swanson, 2005).

Birey yaş, zaman ve mekân sınırı tanımayan yaygın eğitimle hayatının herhangi bir döneminde ihtiyaç duyduğu, istediği eğitimi alabilir. Yaygın eğitim milli eğitimin genel amaçları doğrultusunda bireyin eksik eğitimlerini ta- mamlamasına olanak verir; var olan eğitimini bir üst kademeye çıkarmasına yardımcı olur; bilgilerini güncellemesine; yeni bir meslek edinmesini sağlar. Bireyin kişisel gelişimine katkıda bulunur ve boş zamanlarını daha verimli hale getirir. Örgün eğitimi tamamlayıcı bir rolü de vardır (Murat, 2009; Ültanır ve Ültanir, 2005;).

\subsection{Yetişkin Eğitimi}

Çalışmanın çerçevesinde yaygın eğitimle birlikte yetişkin eğitimi de ele alınmaktadır. Yetişkinler amaç ve sebep-sonuç odaklı olduklarından kendilerini yönlendirmede daha yetkindirler. Kendi öğrenme süreçlerini şekillendirebilirler. Deneyimlerini, birikimlerini ve önceki öğrenmelerini daha bilinçli bir şekilde sonraki aşamalara taşıyabilir. Bu süreçte yaygın eğitimin etkin bir rolü vardır. Yaygın eğitimle yetişkinlerin dikkatlerini belirli bir konuya nasıl çekileceği deneyimlerden yola çıkarak derse ne gibi katkılarda bulunabileceği, dersin etkinlerine nasıl dahil edilebilecekleri gibi hususlar öğretim sürecini desteklemektedir. Yetişkinlerin öğrenme süreçlerini daha etkin kılacak unsurlar olarak da motivasyon, pekiştirme, bilgiyi muhafaza edebilme ve dönüştürebilme de bu bağlamda verilmektedir (Knowles vd., 2005; Lieb, 1991). 


\subsection{Anne Üniversitesi}

Esenler Belediyesi Şehir Düşünce Merkezinin bir projesi olarak geliştirilen Anne Üniversitesi, eğitim ve öğretim hayatına 2012 yılının Ekim ayında, Yıldız Teknik Üniversitesi Davutpaşa Kampüsünde 71 anne ile başladı. Sekiz haftalık bir program olup annelerin rahatlıkla katılabilmesi için hafta sonları 9 ders modülü işlenerek toplamda 48 saat ders verildi. Aralık ayına kadar devam eden bu programdan 61 anne mezun oldu. Birinci dönem bu şekilde tamamlandıktan sonra, ikinci dönem 2013 yılının Nisan ayında başlayıp Mayıs ayında yine aynı program şeklinde tamamland. Bu sefer anne sayısı artarak başvuran 153 anneden 133'ü mezuniyetine hak kazandı. Üçüncü dönem de 2013 yılının Kasım'ında başlayıp 2014 yılının Ocak ayında bitti. Başvuran 93 anneden 61'i sertifika almaya hak kazanmıs olup devamsız olan annelere katılım belgesi verilmemiştir.

Bu kısa tarihçeden sonra, öğrenici kimliği taşıyan bu annelerin eğitim geçmişlerine bakmakta fayda vardır. Örgün eğitimin ilköğretim birinci kademeden veya ortaöğretimden terk gibi eğitimini yarıda bırakmış veya hiç eğitim ala- mamış ya da belli bir süre çalışmış olmasına rağmen mesleki ve iletişimsel becerilerini geliştirmeye ihtiyaç duyan ve bunu dile getiren anneler eğitime tâbi tutulmuştur. Anne Üniversitesi ile annelerin günlük hayatta kendilerini daha rahat ifade edebilmeleri, özgüvenlerini arttırmaları, duyuşsal ve bilişsel gelişimleri kendi çabaları sonucunda hedeflenmiştir. Kendi ifadeleriyle üniversite ortamını soluyarak üniversite hocalarından ders görerek "Üniversiteli Anne" olma ayrıcalı̆̆ kazandırılmaya çalışılmıştır. Böylelikle bir anne olarak aile içindeki rollerinin daha etkin kılınması, kendi sosyal çevrelerinde daha saygın bir konuma gelmeleri ama en önemlisi düşünen, hisseden ve kendi becerilerinin farkında bir birey olarak kendilerini ifade etmeleridir.

$\mathrm{Bu}$ kapsamda ders modülleri hazırlanırken annelerin sadece aile içi görev ve sorumluluklarından ziyade hayatın bütününü kapsayan farklı düşünmeye ve algılamaya yönlendirecek hayat becerilerinin geliştirilmesi ön plânda tutulmuştur. Aşağıdaki tabloda ders modüllerinin adları ve içerikleri verilmiştir:

Tablo 1. Anne Üniversitesi Ders Modülleri

\begin{tabular}{|c|c|c|c|}
\hline Modül Sayısı & Ders ad 1 & Ders süresi & Ders içeriği \\
\hline 1 & İletişim Becerileri & 6 Saat & $\begin{array}{l}\text { Çocuk gelişimi, etkili ebeveyn-çocuk } \\
\text { iletişimi, aile içi iletişim teknikleri ve } \\
\text { kişisel gelişim }\end{array}$ \\
\hline 2 & Değerler Eğitimi & 6 Saat & $\begin{array}{l}\text { Kültürel, sosyal ve dini değerlerimizin } \\
\text { çocuk gelişiminde ve hayat içerisinde } \\
\text { etkili kullanımı }\end{array}$ \\
\hline 3 & Ev Ekonomisi & 6 Saat & $\begin{array}{l}\text { Sağlıklı ve bilinçli beslenme teknikleri } \\
\text { ile ev ekonomisinin geliştirilmesi }\end{array}$ \\
\hline 4 & Düşünce Eğitimi & 6 Saat & $\begin{array}{l}\text { Düşünce nedir? İnsanı var eden } \\
\text { düşünce sistemleri ve özellikle pozitif } \\
\text { düşünme }\end{array}$ \\
\hline 5 & Sanat ve Toplum & 6 Saat & $\begin{array}{l}\text { Sanat tarihi çerçevesinde klasik ve } \\
\text { modern sanatların tanıtılması, Türk } \\
\text { sanatı ile dünya sanatının } \\
\text { ilişkilendirilmesi. Estetik algısının } \\
\text { geliştirilmesi. }\end{array}$ \\
\hline 6 & $\begin{array}{l}\text { Sağlık Bilgisi ve } \\
\text { Çevre Bilinci }\end{array}$ & 6 Saat & $\begin{array}{l}\text { Sigara bırakma semineri ve sağlıklı } \\
\text { beslenme, özellikle çocukların beslen- }\end{array}$ \\
\hline
\end{tabular}




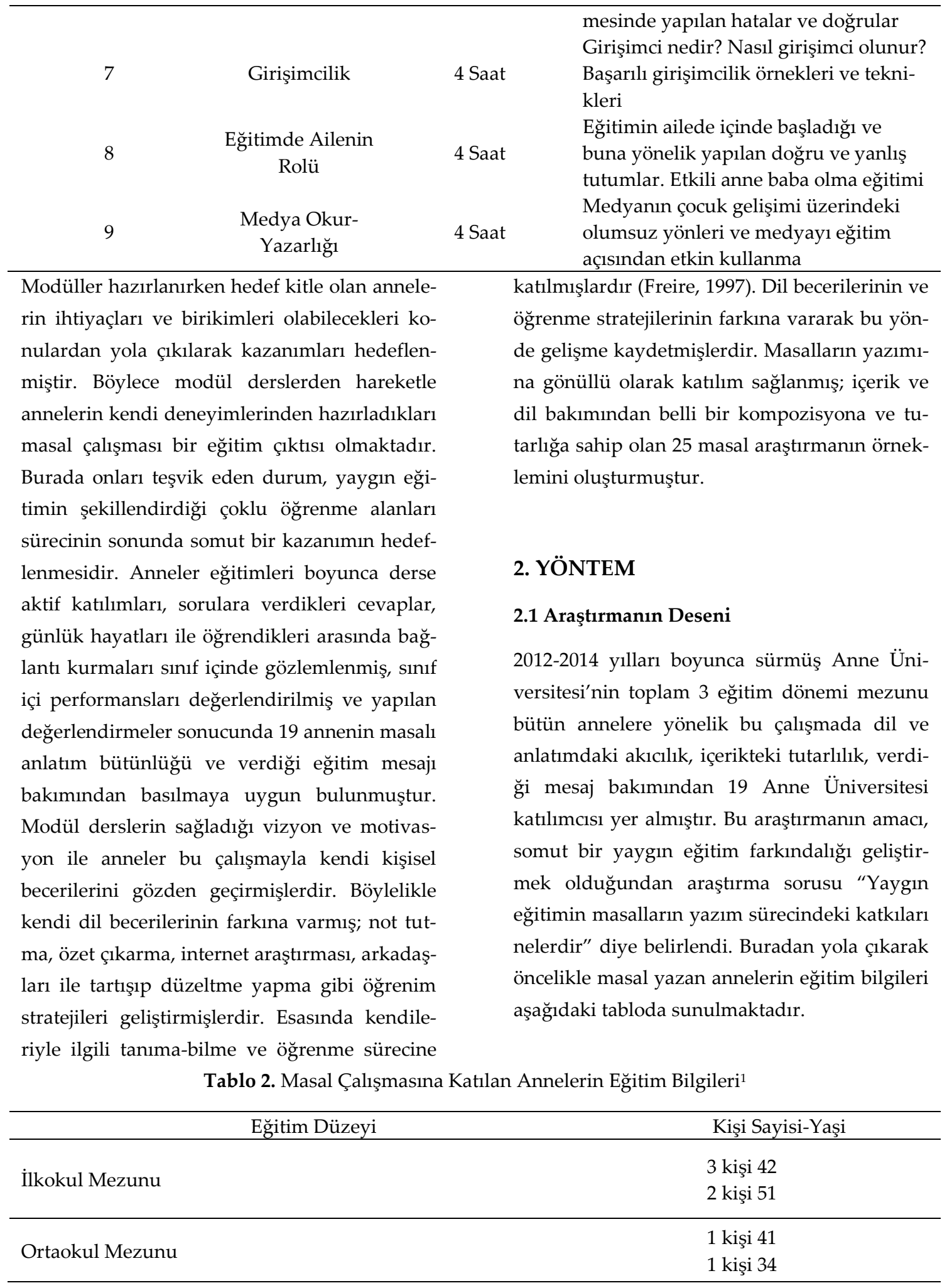

\footnotetext{
${ }^{1}$ Bazı anneler iki masal birden verdiği için sayı burada 19 çıkmaktadır.
} 


\begin{tabular}{l} 
Açık Ortaokulda Okuyor \\
\hline Lise Mezunu \\
\hline Açık Lisede Okuyor \\
Açı Öğretim Fakültesinde Okuyor \\
2.2 Verilerin Toplanması \\
Araştırma verileri masal yazımı üzerine yapı- \\
lan sınıf içi tartışmaların gözlemlenmesi, masal- \\
ların içeriklerinin incelenmesi ve bunlardan \\
elde edilen verilerin sonucunda oluşturulan \\
sözlü ve yazılı yarı yapılandırılmış görüşmeler \\
ile toplandı. Annelerden oluşan masal grubu- \\
nun belirlenmesi için gönüllülük esası temel \\
alınarak, ilgileri doğrultusunda herkese açık bir \\
çalışma sağlandı. Dilsel yeterlilik açısından \\
yapılan eleme sonunda 19 anne, bu çalışmaya \\
kendi yazdıkları masalları göndererek aktif \\
olarak katıldı. Bazı masallar elden, bazıları da \\
e-posta yolu ile toplandı. Masalların öncelikle \\
daha önce hiçbir yerde basılı olmamasına, okul \\
öncesi ve ilköğretim ilk kademede eğitim gören \\
çocukların seviyelerine uygun olmasına ve \\
içeriklerinde olumsuz örnekler içermemesine \\
dikkat edildi. Toplamda 19 anneden 25 masal \\
elde edildi. Masalların yazım süresinde sınıf içi \\
bilgi ve deneyim paylaşımları oldu. Annelerin \\
masallarını oluştururken kendi deneyim ve \\
birikimlerini paylaşarak, sınıf arkadaşlarına ve \\
eğitmene danışarak kompozisyon ve yazma \\
becerilerini geliştirme çabaları gözlemlendi.
\end{tabular}

\section{BULGULAR}

\subsection{Verilerin İncelenmesi}

Yaygın eğitimin belirlediği kavramsal çerçevede masallar tümevarımsal tematik inceleme ile değerlendirilmiştir. Tematik inceleme kuramsal
1 kişi 45

1 kişi 36

1 kişi 37

1 kişi 36

1 kişi 39

2 kişi 39

1 kişi 44

1 kişi 41

1 kişi 49

1 kişi 25

1 kişi 49

bir bakış açısına sahipse de araştırmacıya esnek olma, benzer içeriklerin, temaların ve aralarındaki bağlantıların incelenmesinde esneklik geliştirmeyi ve tekrardan kurgulamayı daha kolay sağlamaktadır (Braun ve Clarke, 2006; Patton, 2002). Toplanan masalların içerikleri yer, zaman, karakterler, konu ve verdiği mesaj olarak sınıflandırıldı. Tematik incelemenin ilk aşamasında içerik benzerlikleri tespit edilerek bir araya getirildi. İkinci aşamada benzer içeriklerden temalar çıarılmaya başlandı. Temaları belirlerken ifadelerdeki benzerlikler ve bağlantılar karşılaştırıldı; araştırma sorusuyla pekiştirilerek tümevarımsal süreç ilerletildi. Üçüncü aşamada elde edilen temalar, araştırma sorusu ile karşılaştırılarak tekrar gözden geçirilip düzeltilerek belirleyici temalara ulaşıldı.

Temaların oluşturulmasında benzer kodlamalarda görülen sosyal-aile hayatına dair benzerlikler ve ilişkilendirmeler dikkatlice araştırıldı. Yaygın eğitimin dil becerilerini nasıl şekillendirdiğini daha iyi anlayabilmek için yarı yapılandırılmış görüşme soruları hazırlandı ve annelere yazılı olarak iletildi. Anneler cevaplarını yazılı olarak verirken anlayamadıkları sorularda veya daha açık ifade etme istedikleri durumlarda sözlü istişarelerde bulunuldu. Görüşmelerden elde edilen veriler, tematik kodlama ile de karşılaştırılarak tekrar ele alınıp gözden geçirildi. Bu yorumlama sürecinde öğrenicilerin gördükleri yaygın eğitimin etkileri tespit edilmeye çalışıldı. Her tema, araştırma 
sorusu "Yaygın eğitimin masalların yazım sürecindeki katkıları nelerdir" ile karşılaştırılıp tekrar değerlendirilerek nihai temalara karar verildi. Araştırmacılar, sınıf içi gözlem notlarını, masalların içeriklerini, görüşme cevaplarını birbirinden bağımsız olarak incelemiş; yaygın ve yetişkin eğitimi alanındaki araştırmaları okuyarak bu çalışmanın güvenirlik ve geçerliliğini sağladı (Patton, 2002).

Annelerin gerçekte yaşadıklarını masallar aracılığıyla aktardıkları, yaygın eğitim formasyonu ile öğrendiklerini birleştirip çıkarımda bu- lundukları; kendileri ile ilgili ileriye dönük mesleki ve eğitimsel hedefler belirledikleri tespit edilmiştir. Bunun sonucunda annelerin kendi hayat tecrübelerinden ne kadar yararlandıkları, yaygın eğitimin eleştirel düşünme, gözden geçirme, yorumlama ve yazma becerilerini nasıl şekillendirdiği bağlamında çıkarımlar yapılmıştır. Aşağıdaki masal adlarından da anlaşılacağı gibi masalların içerikleri, başlıkları ile oldukça örtüşmektedir. Anneler mesajlarını, öğütlerini, tavsiyelerini çok açı bir dille hayatlarından verdikleri örneklerle farklı şekillerde ifade etmektedirler.

Tablo 3. Masalların Listesi

\begin{tabular}{clcl}
\hline Masal sayısı & \multicolumn{1}{c}{ Masalın adı } & Masal sayısı & \multicolumn{1}{c}{ Masalın adı } \\
\hline 1 & Açıgözün oyunu & 13 & Ekmekçik, Ayşecik ve Cikcik \\
2 & Ağlayan Kahvaltı & 14 & Görev \\
3 & Ala İnek & 15 & İyilik \\
4 & Altın Yürek & 16 & Karanlık Dünya \\
& Anne Koyun-Yavru & & \\
5 & Kuzu ve Kurdun & 17 & Kelebeğin Arzusu \\
& Hikâyesi & & \\
6 & Bahadınlı ile Kezban & 18 & Küçük Tüccar \\
7 & Bir Annenin Dramı & 19 & Merhamet \\
8 & Bonibon Gemi & 20 & Mutsuz Çocuk Pelin \\
9 & Çoban & 21 & Neşe ve Cücelerin Maceraları \\
10 & Devin Sonu & 22 & Tek Dişli Nine \\
11 & Doğruluğun Mükâfatı & 23 & Üç Kardeş \\
12 & Dostluk & 24 & Varlık İçinde Yokluk \\
& & 25 & Yaşlı Adam ve Üç Kizı
\end{tabular}

\subsection{Verilerin Değerlendirilmesi}

Her bir masal; tema, karakterler, olayın geçtiği yer ve zaman olarak sınıflandırılmıştır. Karakterler genelde anne-çocuk, baba, kardeşler, diğer aile bireyleri, hayvanlar, dev, çoban gibi şahsiyetlerdir. Yer olarak genelde köy, kasaba ve evin içi seçilmiştir. Belirli bir zaman dilimi belirtilmeyip sadece gece ve gündüz ayrımı yapılmıştır. Çoğunlukla işlenen temalara² baktığımızda ise aşağıdaki liste karşımıza çıkmaktadir:

2 Temaların masallara göre sınıflandırılması makalenin sonunda ek olarak verilmiştir.
- Bencillik-menfaatlerin çatışması, öfke, alay, önyarg1

- Sağlık- Kötü beslenme

- Aile içi ilişkiler - Çocukların/ Kızların korunması, dayanışma, değer verme,

- Özgüven

- Sabır, hoşgörü, kanaat, umut

- Dostluk, yardımlaşma

Masalların içeriklerinden yola çıkarak hazırladığımız sorular gerçek hayat ile yazılan masal arasındaki bağı araştırmaya yönelik olmuştur. Yukarıda belirlenen temaları daha da açıklayıcı sorular sorulmuştur. Diğer bir ifadeyle tematik inceleme sonucunda iki ana kategori belirmiş- 
tir: 1. Masalların içerikleri 2. Gerçek hayatın masala yansıması.

Nesilden nesile aktarılan kültür birikiminde masalın önemi büyüktür. Masalın yaratılma sebepleri arasında "hayal olduğunu, gerçekleşmesinin zor olduğunu bildiğimiz halde ideal ve güzel olanın peşinden gitmek, hayal gücümüz ile var etmek" gibi bir açıklama yer almaktadır. Bu açıklamadan da anlaşılacağı üzere masalların sadece çocukların değil yetişkinlerin de bilişsel ve ruhsal gelişimlerinde etkileri olduğu bir gerçektir (Çıblak, 2005). Masal bilimi incelediğimizde Propp'un aldatma, kötülük, kahramanın tepkisi, çatışma, zafer, giderme, yardım, güç iş, cezalandırma gibi işlevsel birimleri (Kuzu, 2002) ile karşılaşırız; bu çalışmada ele alınan masallarda da bu birimlere rastlamak mümkündür. Özellikle "kötülük, aldatma, cezalandırma, yardım" en belirgin olanlarıdır. Fakat bu çalışmada görülen yaygın eğitimi desteklemesi açısından sadece yaşanılan hayat ile masalla kurulan hayal dünyası arasındaki bağ tespit edilmeye çalışılmıştır.

Aşağıdaki listede annelere masal içeriklerinden yola çıkarak yöneltilen sorulardan elde edilen cevapların sınıflandırılması yapılmış ve kendi hayatları ile yazdıkları masallar arasında nasıl bir ilişkilendirme yaptıkları ortaya konmuştur. $\mathrm{Bu}$ sinıflandırma yapılırken anlatımda kullandıkları ifade ve sözcüklerden yola çıkarak tematik başlıklar oluşturulmuştur. İki araştırmacının birbirinden bağımsız şekilde çalıştıkları tümevarımsal tematik inceleme süreçleri sonucunda bir araya gelinerek ortak temalar karş1laştırılarak belirlenmiştir:

1. Masalın önemi sorusunda öne çıkan temalar, "Doğruluğun Mükâfatı", "Merhamet", "Yaşlı Adam ve Üç Kızı" gibi masallarında adlarından anlaşılacağı üzere, ahlaki ve değer eğitimi, aile içi ilişkilerin önemi, duygusal ve zihinsel gelişimdir.
2. Anneler, masallarındaki konulara nasıl karar verdiklerini açıklarken özellikle aile terbiyesi, aile içi dayanışma ve eğitici olmak üzerinde durmaktadırlar. "Bir Annenin Dramı”, “İyilik”, "Ağlayan Kahvaltı" masallarında ailenin eğitimdeki rolüne dikkat çekilmektedir.

3. Masalı yazarken dikkat edilen noktalar ise deneyimlerden yola çıkarak eğitimli, geleceğe hazır, kendini ifade edebilen bir çocuk yetiştirmek hedeftir. "Anne Koyun-Yavru Kuzu ve Kurdun Hikâyesi", "Mutsuz Çocuk Pelin", "Ayşecik ve Cikcik" adlı eserlerde çocuğun aldığı eğitimle kendini ifade edebilmesi ve gerçek hayat için yetiştirilmesi gerektiğinin altı çizilmektedir.

4. Masalın anlatımında dikkat ettikleri hususlarda ise annelerin Türkçeyi kullanırken ifade ve üslupta ne gibi ölçütler belirledikleri tespit edilmiştir. İçten, açık, akıcı bir dil kullanmaya çalışırken eğitici ve gelecek için ümit vaat eden gerçekçi mesajlar vermeye çalışmışlardır. "Devin Sonu", "Varlık İçinde Yokluk", "Dostluk" hayatın içinden ibret hikâyeleri gibidir.

5. Masalları ile hayatları arasındaki ilişkileri değerlendirdiklerinde çocukları daha güzel bir geleceğe ve hayata hazırlama kaygısı taşıyan, bunun için de aileye önemli bir görev düştüğüne inanan, kişisel gelişime ve eğitime önem veren bir tablo karşımıza çıkmaktadır. "Küçük Tüccar", "Görev", "Kelebeğin Arzusu" adlı masallar aile ve eğitimle geleceğin şekillendiğine dikkat çeken örnekler arasındadır.

6. Bu yaygın eğitim sürecinden sonra kendi gelişimleri ile ilgili neler yapmak istedikleri sorulduğunda, anneler kendilerinin ailelerine ve çevrelerine daha faydalı olabilmek için kişisel gelişim ve eğitimlerine devam etmek istediklerini belirtmişlerdir. "Karanlık Dünya", "Altın Yürek", “Tek Dişli Nine" masalları, eğitimin verdiği öz güvenle kendini ifade ede- 
rek yapılan hizmetlerin nasıl güzel meyveler verdiğini göstermektedir.

$\mathrm{Bu}$ aşamada masalların içerikleri ile bağlantılı sorular karşılaştırılarak araştırmanın güvenirlik ve geçerliliği sağlanmış ve yorumlanan ana temalar belli olmuştur: "Eğitimin ve aile dayanışmasının önemi, gelecekten ümitli olma, çocuğu gerçek hayata hazırlamak". Anneler, aile dayanışmasıyla oluşan eğitim desteğine dikkat çekerek bireyin geleceğinin eğitimle daha iyi olacağı ve gerçek hayatta karşılaşacağı durumlarla daha rahat başa çıkacağı mesajını vermektedirler. Çocuklar gerçek hayatta karşılaşabilecekleri sorunlarla eğitim ve ailenin desteği sayesinde başa çıkabilirler. Eğitim ve aile çocuğu hayata hazırlayan iki önemli etkendir.

Sonuç olarak araştırmada eğitim ve ailenin çocuğu hayata hazırladığı olgusu ön plana çıkmaktadır. Anneler için de görecekleri aile desteği ve alacakları örgün, informal veya yaygın eğitim, gelecekleri ve hayattaki hedefleri için önemlidir. Bu çerçevede eğitim ve aile desteği çıkarımı, araştırmanın sorularına da cevap vermektedir. $\mathrm{Bu}$ araştırma ile yaygın eğitimin katkılarının neler olduğu, Anne Üniversitesi projesi ve "Annemin Masalı" çalışması ile açıklığa kavuşmuştur. Eğitimine ara vermek zorunda kalan annelerin hayat boyu öğrenmesine destek olunmaktadır. Bireyin dezavantajlı geçmişine rağmen hayat-tecrübe merkezli öğrenmeyi hedeflemesi, bilişsel ve iletişim becerilerini geliştirmek için çaba sarf etmesi açıcça gözlemlenmektedir (Vermeersch ve Vandenbroucke, 2009).

Her bir eğitim modülünün sunduğu kazanımların masallardaki izlerini görmek mümkündür. Yaygın eğitimin hayatı plânlayan eğitsel becerileri geliştirmedeki pratik bilgiyi sağladığ göz ardı edilmemelidir. Bu çalışma ile kamu yararına yetişkin bireylere sanat ve kültür eğitimi ile beraber toplumsal etik, sağlık, beslen- me, aile, çevre ve medya-okuryazarlığı eğitimleri de verilmiştir. Bu eğitimin, toplumdaki uyum sorununun giderilmesinde, karşılıklı saygı ve sevginin geliştirilmesinde, farklılıklara hoşgörü ile yaklaşılmasında önemli bir destek olduğu aşikârdır (Egbezor ve Okanezi, 2008).

Eğitim modüllerinin katkısıyla anneler hayat boyu öğrenmede aktif rol alarak "Annemin Masalı" adlı ürün ile somut bir öğrenim çıtısı elde etmişlerdir. Yalnız burada yaygın-yetişkin eğitiminde öğrenme verimliliğinin altı çizilmelidir. Eğitimciler, genelde bütün öğrenicilerin, üç önemli öğrenme alanı olan bilişsel, duyuşsal, psikomotor alanlarının hepsini kapsayan etkinliklerden daha fazla yararlandıklarını söylerler. Bilişsellik konu-içeriğe, duyuşsallık tutum ve inançlara, psikomotor tatbiki uygulamaya gönderme yapar. Modüllerde işlenen konularla annelerin bilişsel becerileri; günlük hayatla, tutum ve inançlarla bağlantılar kurularak duyuşsal becerileri; verilen ödevler ve sınıf içi etkinliklerle de psikomotor becerileri geliştirilmiştir (Forehand, 2012). Bu üç öğrenme alanını içeren "Annemin Masalı" çalışması ise bütün bu becerilerin bir kazanımıdır. Daha sonra düzenlenecek etkinlere de örnek olacaktır. Anne olmanın verdiği sorumlulukla görev odaklı olmaları, hayatlarında zaten daimi yaptıkları etkinliklerden verimliliğe geçişleri de bu çalışmaya artı bir değer katmıştır.

\section{SONUÇ}

Yaygın eğitim, çıktı merkezli, bireyselleştirilmiş, uygulanabilir bir süreçtir. Bu süreçte öğrenmenin kültürel ve sosyal boyutu ön plânda tutulmaktadır. Bunun için de bireyin öğrenme stratejilerinin, kültürel ve sosyal bir bağlama oturtulması önemlidir (Hussain, 2013). Bu çerçevede "Annemin Masalı" çalışması, annelerin öğrenme stratejilerini geliştirerek özsaygıla- 
rını artırmış, hayat-tecrübe merkezli bir eğitim çıtısı haline gelmiştir.

Annelerin öğrenme becerilerinin yanı sıra okuryazarlıklarının da pekiştirilmesi söz konusudur. Kadının informal okuryazarlığı kendi yerel çevresinde organik bir entelektüel olma sürecine girmiştir. Gramsci, “organik entelektüellerin" sosyal değişimde merkezi bir rol oynadığını söyler. Kadınlar, kaydettikleri bu eğitim aşamaları ile hayatlarında olumlu değişiklikler yapmışlardır (Gramsci 1971, Akt. Takayanagi, 2013: 54). Bunun sonucunda da dönüşümsel öğrenmenin gerçekleştiği ve kişiyi hem bireysel hem de sosyal seviyede daha da özgürleştirdiği belirgindir. Esasında bu dönü- şüm, kişinin kendi becerileri, estetik algısı, kültürel ve sosyal birikimleri ile birlikte farkındalıklarının artmasıdır. Kendi kendine eleştirel bir gözle bakıp mütalaalarda bulunabilmesidir (Dirkx, 1998). Böylece hayatına yeni hedefler ve yeni anlamlar katacaktır. Yazdıkları masallar ile dil ve anlatım becerilerini gösterirken kendini ifade edebilme ve dili daha estetik kullanma güçlerini de test etmişlerdir. Birikim, tecrübe, anılardan yola çıkarak topluma vermek istedikleri mesajlar aslında bir nevi hayat bilgisini somutlaştırmış; masal üzerinden kendisi ve toplum arasında diyalektik bir ilişki kurulmuştur.

\section{Kaynakça}

Braun, V., ve Clarke, V. (2006). Using Thematic Analysis in Psychology. Qualitative Reseach in Psychology, $3(2), 77-101$.

Çıblak, N. (2005). V. Propp'un Masal Çözümleme Metodu. Türk Dili, 638, 127-140.

Dirkx, J. M. (1998). Transformative Learning Theory in the Practice of Adult Education: An Overview. PAACE Journal of Lifelong Learning, 7, 1-14.

Egbezor, D. E. ve Okanezi, B. (2008). Non-Formal Education as a Tool to Human Resources Development: An Assessment. International Journal of Scientific Research in Education, 1(1), 26-40.

Eloranta, L. (2013). Innovation in a Non-Formal Adult Education Organisation - multi-case study in four adult education centres, Thesis for the degree of Doctor of Science(technology). Erişim tarihi 14 Eylül 2014, www.doria.fi/bitstream/handle/

Eurydice, (2011). Modernisation of Higher Education in Europe: Funding and the Social Dimension. Erişim tarihi 09 Ekim 2014, http://eacea.ec.europa.eu/education/eurydice.

Forehand, M. (2012). Bloom's Taxonomy. Erişim tarihi 03 Ocak 2015, http://www4.edumoodle.at/gwk/pluginfile.php/109/mod_resource/content/5/forehand bloomsch etaxonomie02.pdf

Freire, P. (1997). Pedagogy of The Oppressed. New Revised 20th-Anniversay Edition: Continuum Newyork,

Hussain, M. S. (2013). Challenges and Emerging Perspectives in Adult Education Delivery in Nigeria. European Scientific Journal, 9.(13), 138-145.

Knowles, M.S., Holton, E.F. ve Swanson, R.A. (2005). The Adult Learner: the definitive classic in adult education and human resource development. 6 th ed. Elsevier. 
Knox, A. B. (2002). Evaluation for Continuing Education A Comprehensive Guide to Success, Jossey-Bass.

Kuzu, T. (2002). Masalın Değişmez Yasaları - İşlevsel Birimler -. Anadolu Üniversitesi Edebiyat Fakültesi Dergisi, Edebiyat Fakültesi Yayınları, 10(3), Eskişehir, 219-229.

Murat, S. (2009). Dünden Bugüne İstanbul'da Yaygin Eğitim. İstanbul Tic. Odası Yayınları Yayın No: 20098. Erişim tarihi 16 Eylül 2014, www.ito.org.tr/itoyayin/0020791.pdf

Ngaka, W., Openjuru, G., Mazur, R.E. (2012). Exploring Formal and Non-Formal Education Practices for Integrated and Diverse Learning Environments in Uganda. The International Journal of Diversity in Organizations, Communities and Nations, 11(6), 109-121.

Patton, M. Q. (2002). Qualitative Research and Evaluation Methods. Thousand Oaks, CA: Sage.

Takayanagi, T. (2013)，タカヤナギタエコ，\& 高柳妙子. Rethinking literacy: A case study exploring women's informal learning in coastal Kenya. CICE 叢書 5 Africa-Asia University Dialogue for Educational Development: Final Report of the Phase II Research Results:(1) Gender and Equity, 51-63. Erişim tarihi $14 \quad$ Eylül 2014, http://home.hiroshima-u.ac.jp/cice/wpcontent/uploads/publications/series/5-1/5-1-41.pdf

Ültanır, E., Ültanır, G. (2005). Estonya, İngiltere ve Türkiye'de Yetişkinler Eğitiminde Profesyonel Standartlar. Mersin Üniversitesi Ĕ̆itim Fakültesi Dergisi, 1(1), 1-23.

Vermeersch, L., Vandenbroucke, A. (2009). The Access of Adults to Formal and Nonformal Adult Education Country report: Belgium (Flemish Community). LLL2010 project, Subproject 5. K.U.Leuven (University of Leuven) - Higher Institute for Labour Studies: Leuven. 


\section{Extended Summary}

The Project "Mother University" and the activity "My Mother's Tale" showed us that non-formal eduction could be effective at every stage of life. It was observed that despite of having disadvantaged background, an individual could develop his/her cognitive and communicative skills through life-experience centered learning (Vermeersch ve Vandenbroucke, 2009). The education requires to be accepted within the integrity of life rather than making classifications of traditional, formal, non-formal, adult and informal education. Each educational unit offers unique oppotunities. It should not be ignored that non-formal education provides practical knowledge which cultivates educational skills for planning life. With this research, the adult learners were taught aesthetics, culture and social ethics for the sake of public interest. It is obvious that non-formal instruction supports to resolve the compliance issues, to establish mutual respect and tolerance to diminish the differences among the people in the society (Egbezor ve Okanezi, 2008).

Moreover, non-formal education motivates the learner to take a more active role in the community and to be able to make decisions by herself with having self-esteem. Non-formal education is an output-centered, individualized and practicable process. Particularly, cultural and social dimensions of learning are taken into considereation in this process. Therefore, it is important to set up the learning strategies within cultural and social context (Hussain, 2013). The reseach "My Mother's Tale" made the women raise their self-esteem with improving their learning strategies, and eventually became life-experience centered educational output.

Nevertheless, we need to highlight the effective learning at non-formal adult education. Generally, the instructors tell that all learners benefit more from the activities which include all three main learning domains; cognitive, affective and psychomotor learning. Briefly, cognition domain refers to subject-content; affection refers to attitude and beliefs; psychomotor refers to practical application. In the modules, the cognitive skills of the mothers have been imroved through studying subject-matters; the affective skills have been cultivated through connecting attitude and beliefs with daily life; lastly, homeworks and classroom activities have ameliorated their psychomotor skills (Forehand, 2012). The study "My Mother's Tale", which includes all these three learning domains, is also an outcome of all these skills. It will be an outstanding example for further nonformal education research.

The responsibility of being mother consciously enables them to become task-oriented individuals and this drives them performing some activities permanently and instinctively. At this point, non-formal education provides the transitions from constant activities to the effective learning. Thus, these transitions would contribute to the study with additional values.

The mothers' learning skills have been dealt with reinfocing their literacy skills as well. The informal literacy of the women has entered into the process of becoming an organic intellectual in her own local setting. Gramsci says that "organic intellectuals" play a central role at the social changes (Gramsci 1971, Akt. Takayanagi, 2013: 54). Based on this argument, in the study "My Mother's Tale", the women were able to make positive changes in their life with these transitional educational stages. Consequently, transformational learning has occured and liberated the woman individually and socially from their stereotyped duties and roles. Basically, this transformation is raising awareness of the women on their own personal skills, aesthetic perception, cultural and social knowledge. Moreover, it leads them to critize and reflect on themselves (Dirkx, 1998). Thus, they will be able to integrate new objectives and meanings into their life. While they exhibit their language and narration skills by authoring the tales, they take forward their capacity of self expression too. In addition to this, they find the opportunity to test themselves on their Turkish language knowledge. They want to give messages to the society depending on their background, experiences and memories, so this attempt actually involves the knowledge of life and conveys it from theoretical framework to practice. Finally, within the style of tale, it establishes a dialectic relationship between self and society. 


\section{Ek-1}

\section{MASALIN ÖNEMI SORUSUNDA ÖNE ÇIKAN TE- MALAR}

Duygusal ve zihinsel gelişimin önemi

İbret almak

İç dünyasının zengin olması

SORU 1

Geçmiş ve gelecek ile bağ kurmak

Kendini İfade edebilmek

Özgüven sahibi olmak

Aile bağının kuvvetli olması
TEMANIN GEÇTIĞİ MASALIN MASAL

ADI

SAYISI

Ekmekçik, Ayşecik ve Cikcik, Üç

Kardeş, İyilik, Çoban, Merhamet,

Tek Dişli Nine, Bonibon Gemi,

Ağlayan Kahvaltı, Bahadınlı ile

Kezban, Altın Yürek, Küçük

Tüccar, Yaşlı Adam ve Üç Kızı

Doğruluğun Mükâfatı, Ağlayan

Kahvaltı, Bonibon Gemi, Bahadın-

lı ile Kezban, Altın Yürek, Küçük

Tüccar, Yaşlı Adam ve Üç Kızı

Üç Kardeş, Çoban, Merhamet,

Dostluk, Bonibon Gemi, Ağlayan

Kahvaltı, Ala İnek, Karanlık

Dünya, Yaşlı Adam ve Üç Kızı,

Kelebeğin Arzusu, Görev,

Doğruluğun Mükâfatı, Anne

Koyun-Yavru Kuzu ve Kurdun

Hikâyesi, Mutsuz Çocuk Pelin,

Tek Dişli Nine, Neşe ve Cücelerin 9

Maceraları, Bahadınlı ile Kezban,

Küçük Tüccar, Altın Yürek, Yaşlı

Adam ve Üç Kızı

Mutsuz Çocuk Pelin, Dostluk,

Varlık İçinde Yokluk, Açıkgözün

Oyunu, Ağlayan Kahvaltı, Boni-

bon Gemi, Açıkgözün Oyunu,

Devin Sonu

Açıkgözün Oyunu, Devin Sonu, Ekmekçik, Ayşecik ve Cikcik, İyilik, Varlık İçinde Yokluk, Dostluk, Neşe ve Cücelerin Maceraları

Bir Annenin Dramı, Yaşlı Adam ve Üç Kızı, Merhamet, Tek Dişli Nine

\section{ANNELER MASALLARINI YAZARKEN KONUYA NASIL KARAR VERDİKLERİ}

TEM

ADI

MASAL

Ekmekçik, Ayşecik ve Cikcik, İyilik, Varlık İçinde Yokluk, Bir

Eğitici olması Annenin Dramı, Neşe ve Cücelerin Maceraları, Görev, Kelebeğin Arzusu

SORU 2

Güzel ahlakı aktarmak (merhamet, masumiyet, iyilik, dostluk, ümitli olmak, yardımlaşma)

Üç Kardeş, İyilik, Çoban, Merhamet, Altın Yürek, Küçük Tüccar
Mutsuz Çocuk Pelin, Bahadınlı ile 4 Kezban 
Çocuklara hitap edebilmek ve örnek olmak

Aile içi ilişkiler

Kendini ifade edebilmek

Gerçek hayat

\section{SORU 3}

Deneyimler

Eğitici olmak

Yarınlar için ümit vermek

\section{MASALIN ANLATIMINDA DİKKAT ETTİKLERİ} UNSURLAR

Şiir dili gibi ahenkli bir dil kullanmaya çalışmak

SORU 4

İçten, anlaşılabilir, açık, akıcı bir anlatım kullanmak
Ekmekçik, Ayşecik ve Cikcik, İyilik, Anne Koyun-Yavru Kuzu ve Kurdun Hikâyesi, Dostluk, Bir Annenin Dramı, Neşe ve Cücelerin Maceraları, Görev, Kelebeğin Arzusu

Doğruluğun Mükâfatı, Mutsuz Çocuk Pelin, Tek Dişli Nine, Devin Sonu, Açıkgözün Oyunu, Bonibon Gemi, Ağlayan Kahvaltı, Karanlık Dünya, Ala İnek, Bahadınlı ile Kezban, Küçük Tüccar, Altın Yürek, Yaşlı Adam ve Üç Kiz1

$\begin{array}{ll}\text { TEMANIN GEÇTİĞİ MASALIN } & \text { MASAL } \\ \text { ADI } & \text { SAYISI }\end{array}$

Ekmekcik, Ayşecik ve Cikcik, Mutsuz Çocuk Pelin, Dostluk, Varlık İçinde Yokluk, Neşe ve Cücelerin Maceraları, Yaşlı Adam ve Üç Kızı,

Doğruluğun Mükâfatı, Üç Kardeş, Mutsuz Çocuk Pelin, Varlık İçinde Yokluk, Ağlayan Kahvaltı, Bahadınlı ile Kezban,

Ekmekcik, Ayşecik ve Cikcik, Doğruluğun Mükâfatı, Üç Kardeş, Çoban, Tek Dişli Nine, Açıkgözün 10 Oyunu, Devin Sonu, Ala İnek, Karanlık Dünya İyilik, Merhamet, Anne KoyunYavru Kuzu ve Kurdun Hikâyesi, Bonibon Gemi, Neşe ve Cücelerin Maceraları, Bir Annenin Dramı, Küçük Tüccar, Altın Yürek, Görev, Kelebeğin Arzusu

Neşe ve Cücelerin Maceraları, Küçük Tüccar, Altın Yürek, Gö5 rev, Kelebeğin Arzusu

$\begin{array}{ll}\text { TEMANIN GEÇTIGĞI MASALIN } & \text { MASAL } \\ \text { ADI } & \text { SAYISI }\end{array}$

Ekmekcik, Ayşecik ve Cikcik 1

Doğruluğun Mükafatı, Üç Kardeş, İyilik, Merhamet, Anne KoyunYavru Kuzu ve Kurdun Hikayesi, Dostluk, Varlık İçinde Yokluk, Devin Sonu, Açıgözün Oyunu, 16 Ala İnek, Karanlık Dünya, Bahadınlı ile Kezban, Bir Annenin Dramı,Yaşlı Adam ve Üç Kızı, Görev, Kelebeğin Arzusu 
Eğitici ve gelecek için ümit vaat eden mesajlar vermek

MASALLARI İLE HAYATLARI ARASINDAKİ İLIŞKİ

Kendini İfade edebilmek

Gerçek hayattan deneyimler aktarmak

SORU 5 Yarınlar için ümitli olmak

Başkalarına iyilik yapmak ve yardım etmek

Çocuklara daha güzel bir gelecek hazırlamak

Hayattaki kişisel dönüşümler ve gelişimler
Çocuklara uygun konuları seçmek

Ailenin önemi

Anne Koyun-Yavru Kuzu ve Kurdun Hikâyesi, Dostluk, Varlık İçinde Yokluk, Ağlayan Kahvaltı, Bonibon Gemi, Karanlık Dünya, Ala İnek, Altın Yürek, Küçük Tüccar, Görev, Kelebeğin Arzusu Üç Kardeş, Çoban, Tek Dişli Nine, Ağlayan Kahvaltı, Bonibon Gemi, Neşe ve Cücelerin Maceraları, Küçük Tüccar, Altın Yürek

TEMANIN GEÇTIIĞİ MASALIN ADI

Ekmekcik, Ayşecik ve Cikcik, Çoban, Merhamet, Mutsuz Çocuk Pelin, Varlık İçinde Yokluk, Dostluk, Ağlayan Kahvaltı, Altın Yürek, Küçük Tüccar Ekmekcik, Ayşecik ve Cikcik, Çoban, Merhamet, Mutsuz Çocuk Pelin, Ağlayan Kahvaltı, Bir Annenin Dramı, Küçük Tüccar, Görev, Kelebeğin Arzusu Üç Kardeş, Altın Yürek, Küçük Tüccar

İyilik, Neşe ve Cücelerin Maceraları

Varlık İçinde Yokluk, Dostluk

Merhamet, Devin Sonu, Açıkgözün Oyunu, Ağlayan Kahvaltı

Doğruluğun Mükâfatı, Mutsuz Çocuk Pelin, Ağlayan Kahvaltı, Küçük Tüccar, Altın Yürek, Görev, Kelebeğin Arzusu

BU ÇALIŞMADAN SONRA KENDİ GELISŞİMLERİ İLE İLGİLI NELER YAPMAK İSTEDİKLERİ

TEMANIN GEÇTİĞİ MASALIN ADI

Ekmekcik, Ayşecik ve Cikcik, Merhamet, Mutsuz Çocuk Pelin,

Eğitime devam etmek istedikleri Ala İnek, Karanlık Dünya, Neşe ve Cücelerin Maceraları, Yaşlı Adam ve Üç Kızı

SORU 6

Doğruluğun Mükâfatı, Merhamet, Anne Koyun-Yavru Kuzu ve Kurdun Hikâyesi, Tek Dişli Nine, Devin Sonu, Açıkgözün Oyunu, Bonibon Gemi, Ağlayan Kahvaltı, Bahadınlı ile Kezban, Bir Annenin Dramı, Altın Yürek, Küçük Tüccar, Görev, Kelebeğin Arzusu 
Hizmete daha çok önem verecekleri

Dayanışma ve yardımlaşmanın önemi

Ailemize ve çevremize karşı sosyal duyarlılığın geliştirilmesi

Özgüven sahibi olmak

Kendini İfade etmek

Motivasyonu canlı tutmak
Anne Koyun-Yavru Kuzu ve Kurdun Hikâyesi, Dostluk, Açıkgözün Oyunu, Küçük Tüccar, Altın Yürek, Görev, Kelebeğin Arzusu

Dostluk, Açıkgözün Oyunu, Küçük Tüccar, Altın Yürek

Çoban, Anne Koyun-Yavru Kuzu ve Kurdun Hikâyesi, Yaşlı Adam 3 ve Üç Kızı

Anne Koyun-Yavru Kuzu ve Kurdun Hikâyesi, Mutsuz Çocuk

Kişisel gelişimin, eleştirel ve yaratıcı düşünmenin önemi Pelin, Bir Annenin Dramı, Yaşlı Adam ve Üç Kızı, Görev, Kelebeğin Arzusu İyilik, Tek Dişli Nine, Ağlayan Kahvaltı, Bonibon Gemi, Neşe ve 5 Cücelerin Maceraları

İyilik, Neşe ve Cücelerin Maceraları,

Üç Kardeş, Varlık İçinde Yokluk, Dostluk, Altın Yürek, Küçük Tüccar 